\title{
Chemical Enhanced Oil Recovery Technology in Shengli Oilfield
}

\author{
SHI Jing, YUAN Fuqing, GUO Lanlei and CAO Xulong \\ Exploration and Development Research Institute of Shengli Oilfield Company, SINOPEC, Dongying, \\ Shandong, China \\ Email: shijing637.slyt@sinopec.com
}

Keywords: chemical flooding; polymer flooding; surfactant/polymer flooding; heterogeneous flooding, enhanced oil recovery

\begin{abstract}
The original oil in place suitable for chemical flooding in Shengli oilfield is 1.6 billion ton. Though the resource is abundant, the oil recovery is poor due to rigorous reservoir conditions, including high temperature, high salinity, high divalent-cation content, high oil viscosity and severe heterogeneity. In an effort to counteract the rigorous reservoir conditions, polymer flooding technologies for class I and II reservoirs has been improved, and surfactant/polymer flooding has been implemented industrially. Heterogeneous combination flooding technology has made great breakthroughs. A unique series of chemical flooding technologies has been developed and played a significant role in maintaining oil production in mature fields.
\end{abstract}

\section{Introduction}

The original oil in place (OOIP) suitable for chemical flooding in Shengli oilfield is $16.05 \times 10^{8}$ ton [1]. Though the available chemical flooding resources are tremendous, the reservoir conditions are difficult in terms of the high temperature, high salinity, high divalent-cation content, high oil viscosity and severe heterogeneity. Stricter requirements have been established for reservoir recognition and residual oil distribution studies, heat-resistant and salt-tolerant capabilities and the viscofication of displacement systems. To counteract the rigorous reservoir conditions, a unique series of chemical flooding technologies has been developed.

\section{Chemical Flooding in Shengli Oilfield}

By the end of 2016,59 chemical flooding projects with an overall OOIP of $4.46 \times 10^{8}$ ton had been implemented in Shengli oilfield. Chemical floods have contributed to an annual oil increment of $1.5 \times 10^{6}$ ton for twelve continuous years. The cumulative oil increment due to chemical floods has reached $29.01 \times 10^{6}$ ton. It is estimated that the total incremental recovery will be $8.1 \%$, and the recoverable reserve will increase by $36.15 \times 10^{6}$ ton.

\section{Chemical Flooding Technologies}

With the continuing large-scale industrial application of chemical flooding, the remaining reservoir conditions are becoming increasingly harsh. This situation has spurred the development of new displacement systems with higher sweep efficiency and displacement efficiency. To help counteract the challenges of class III high-temperature and high-salinity reservoirs, class IV high-permeability reservoirs, and reservoirs after polymer flooding, novel chemical flooding systems, such as surfactant/polymer flooding systems and heterogeneous combination flooding systems have been developed.

Polymer flooding. It is well known that the mobility ratio plays an important role in oil recovery [2]. However, the viscosity of the polymer solution changes constantly during percolation, making the mobility ratio of polymer flooding difficult to determine $[3,4]$. To solve this issue, the correlation between the viscosity ratio of the polymer solution to oil and the enhanced recovery was studied. A 
reasonable viscosity ratio range was determined to be $0.15 \sim 0.5$, with a comparatively large recovery increment magnitude. Numerical and physical simulations yielded consistent results (see Fig.1).

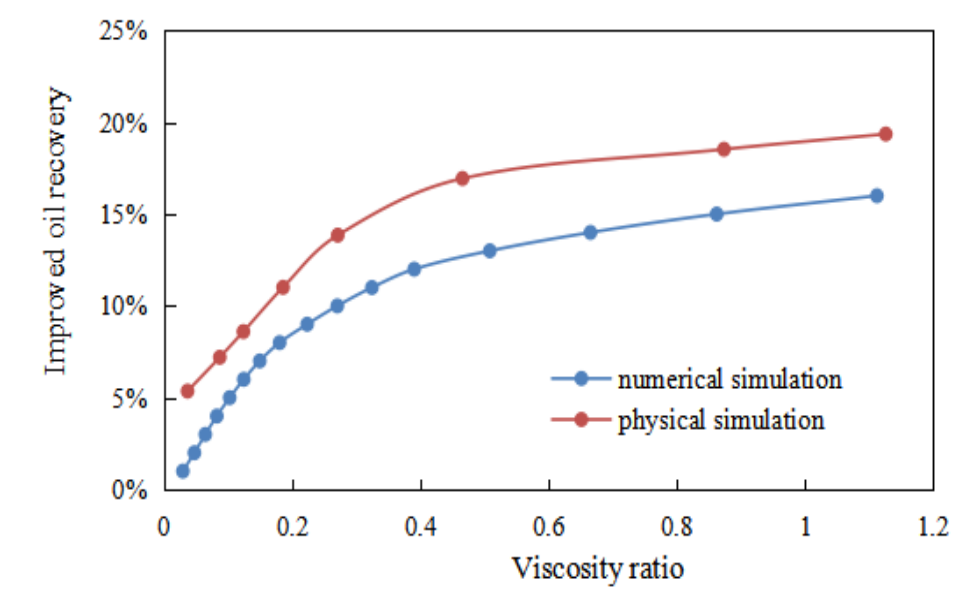

Fig. 1 Correlation between viscosity ratio of polymer solution to oil and enhanced recovery

Partially hydrolyzed polyacrylamide (HPAM) with a molecular weight of $15 \times 10^{6}$ was chosen for class I reservoirs. Its viscosity satisfied the requirements of $20 \mathrm{mPa} \bullet \mathrm{s}$ at $1500 \mathrm{mg} / \mathrm{L}$. The formulation of polymer flooding for class I reservoirs was $0.05 \mathrm{PV} \times 2000 \mathrm{mg} / \mathrm{L}+0.20 \mathrm{PV} \times 1500 \mathrm{mg} / \mathrm{L}$. HPAM was prepared using fresh water and injected using produced water. A pilot polymer flooding application was conducted at Gudao's ZYQ Ng3 (a class I reservoir) in 1992. The reservoir parameters were as follows: oil viscosity at the surface of $46.3 \mathrm{mPa} \cdot \mathrm{s}$, formation temperature of $70{ }^{\circ} \mathrm{C}$, salinity of 5293 $\mathrm{mg} / \mathrm{L}$, divalent cation content of $102 \mathrm{mg} / \mathrm{L}$, and OOIP of $1.65 \times 10^{6}$ ton. An injection of 1389.5 ton of polymer yielded a maximum water cut reduction of $19.3 \%$ (from $90.3 \%$ to $71.0 \%$ ) and an increase in oil production from 122 ton/day to 351 ton/day (see Fig.2). The cumulative incremental oil production was $20 \times 10^{4}$ ton, while the enhanced recovery was $12.0 \%$ over waterflooding, and the incremental oil per ton of polymer was 143 ton.

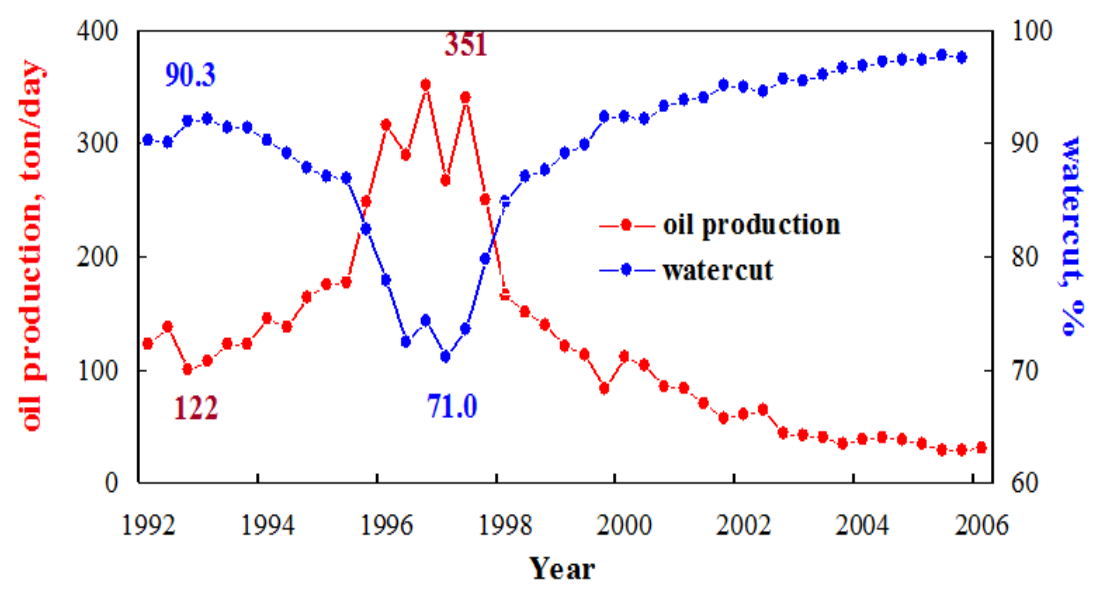

Fig. 2 Production curve of polymer pilot at Gudao's ZYQ Ng3

HPAM with a molecular weight of $20 \times 10^{6}$ was suitable for class II reservoirs. Its viscosity reached $20 \mathrm{mPa} \cdot \mathrm{s}$ at $1500 \mathrm{mg} / \mathrm{L}$. In contrast, the viscosity of $1500 \mathrm{mg} / \mathrm{L}$ HPAM with a molecular weight of $15 \times 10^{6}$ was only $9.3 \mathrm{mPa} \bullet \mathrm{s}$. A pilot polymer flooding application was conducted at Shengtuo's SYQ (a class II reservoir) in 1998. The reservoir parameters were as follows: oil viscosity at the surface of $25 \mathrm{mPa} \cdot \mathrm{s}$, formation temperature of $80^{\circ} \mathrm{C}$, salinity of $21000 \mathrm{mg} / \mathrm{L}$, and divalent cation content of 311 mg/L. From April 1998 to September 2001, 7005.7 ton of polymer was injected. After applying polymer flooding, the maximum water cut reduction reached $15.4 \%$ (from $95.9 \%$ to $80.5 \%$ ), and oil production increased from 177 to 558 ton/day (see Fig. 3). The cumulative oil increment was 
$71.5 \times 10^{4}$ ton. The incremental recovery was $6.6 \%$ OOIP over waterflooding, and the incremental oil per ton of polymer was 102 ton. It is estimated that the final enhanced recovery and oil increment per ton of polymer will be $7.0 \%$ and 109 ton, respectively.

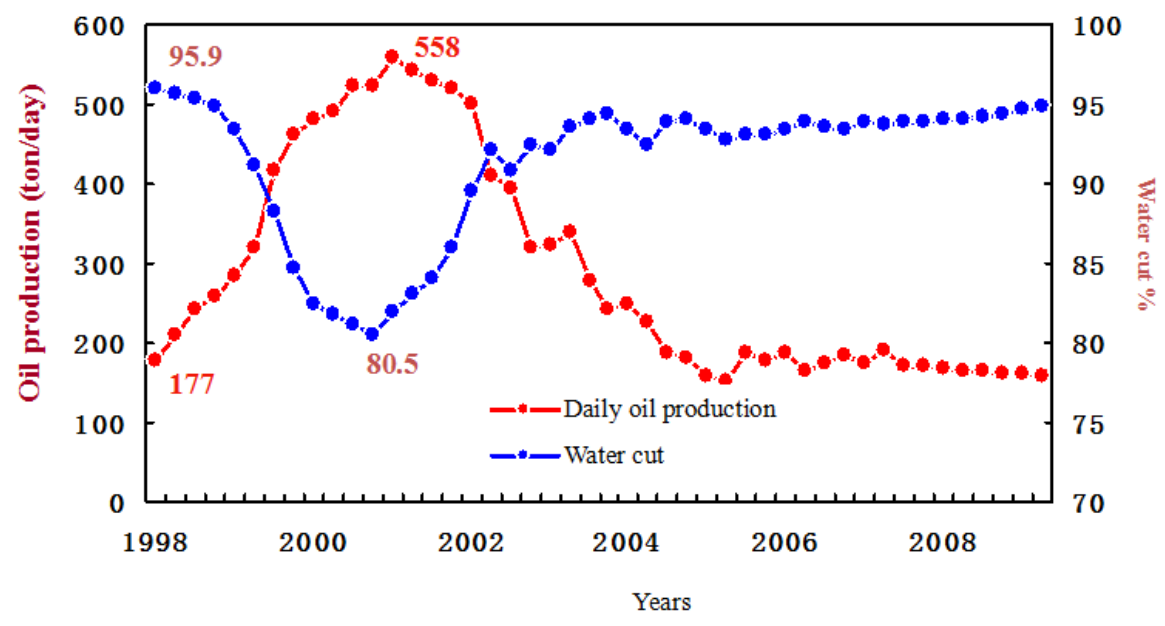

Fig. 3 Production curve of polymer pilot at Shengtuo's SYQ

So far, 30 polymer flooding projects have been implemented in class I and II reservoirs, with an OOIP of $3.2 \times 10^{8}$ ton. The cumulative oil increment was $18.88 \times 10^{6}$ ton, equivalent to $7.1 \%$ OOIP of recovery.

Surfactant/polymer flooding. Research on combination flooding, mainly alkaline/polymer/surfactant (ASP) and surfactant/polymer (SP) flooding, began in the late 1980s. It has been suggested that ASP and SP techniques could improve oil recovery by 12 20\% OOIP.

Considering the high acid value of Shengli crude oil, ASP flooding was considered first. The first pilot of ASP flooding in China was conducted at Gudong in 1992. The water cut of the central wells already had exceeded $98 \%$ for three years before the pilot. After applying the ASP system, the water cut of the central wells declined from $99.3 \%$ to $85.2 \%$, and the cumulative incremental oil production increased to 1740 ton. The enhanced oil recovery was $16.8 \%$, and the oil increment per ton of polymer was 110 ton. By the end of the ASP pilot, 76.2\% OOIP was obtained in the central wells [5-6]. After the great success of the pilot test, ASP flooding was extended to western Gudao in 1997. From May 1997 to April 2002, the cumulative incremental oil production and recovery were $29.6 \times 10^{4}$ ton and $15.5 \%$, respectively.

Despite the high recovery factor of ASP flooding, the scale deposit in the injection system was a serious issue. Additionally, the produced fluids contained a large number of emulsions, which were difficult to break. Therefore, the industrial application of ASP flooding was restricted. To avoid the problems caused by ASP flooding, an alkali-free surfactant/polymer system was developed. The first SP pilot was conducted at Gudong's QQX in 2003. The parameters were as follows: oil-bearing area of $0.94 \mathrm{~km}^{2}$, OOIP of $2.77 \times 10^{6}$ ton, 10 injectors and 16 producers, with a distance between each injector and producer of $300 \mathrm{~m}$, oil viscosity at the surface of $40.1 \mathrm{mPa} \bullet \mathrm{s}$, formation temperature of $68{ }^{\circ} \mathrm{C}$, total salinity of the formation water of $7883 \mathrm{mg} / \mathrm{L}$, and divalent cation content of $244 \mathrm{mg} / \mathrm{L}$. The total water cut was $98.3 \%$ before the SP pilot. After the application of SP flooding, the water cut in the central wells dropped to $60.4 \%$, and oil production increased from 10.4 to 127.5 ton/day (see Fig. 4). The cumulative oil increment in the central wells was $12.2 \times 10^{4}$ ton, and the enhanced recovery was $18.0 \%$ OOIP. The cumulative oil increment over the entire pilot area was $24.7 \times 10^{4}$ ton, and the enhanced recovery was $8.9 \%$. 


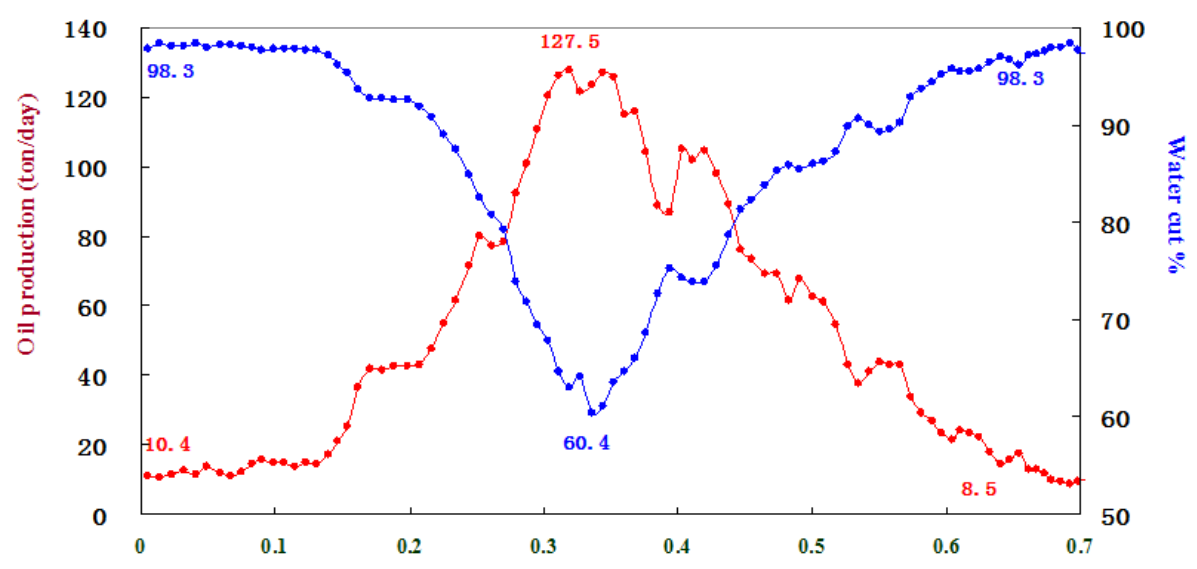

Fig. 4 Production curve of SP pilot at Gudong's QQX

The large-scale industrial application of SP flooding began in 2007. By the end of 2016, 21 SP projects had been conducted in the Gudao, Gudong, Shengtuo and Chengdong fields. The producing reserves were $1.5 \times 10^{8}$ ton, with a cumulative incremental oil production of $9.57 \times 10^{6}$ ton. The oil increment of SP flooding in 2012 accounted for $62 \%$ of the chemical flooding oil increment in Shengli oilfield. The recoverable reserves and oil recovery had increased by $1052 \times 10^{4}$ ton and $10.2 \%$, respectively. SP flooding has become an important contribution to oil production in Shengli oilfield.

Heterogeneous combination flooding. The OOIP of reservoirs after polymer flooding in Shengli oilfield was $2.9 \times 10^{8}$ ton. The average oil recovery was only $46.0 \%$, implying that $54.0 \%$ of reserves remained underground. Core tests and dynamic monitoring data have revealed that the heterogeneity becomes more severe after polymer flooding. A novel heterogeneous combination flooding (HCF) system was developed that consists of branched preformed particle gel (B-PPG), polymer and surfactant. B-PPG is a kind of injectable soft solid displacement agent, in which partly crosslinked 3D-network and partly star-branched polymer chains are co-existed. Partly crosslinked 3D network forms swelling deformable viscoelastic particle. Branched polymer chains are soluble to increase viscosity. Therefore, B-PPG is suitable for conformation control and oil displacement. Physical simulation experiments showed that the HCF system improved oil recovery by $13.6 \%$ over polymer flooding.

The HCF pilot was conducted at Gudao's ZYQ Ng3 in October 2010 with 15 injectors and 10 producers. It had a line drive well network with well spacing of $135 \times 150 \mathrm{~m}$. The water cut and oil recovery before the pilot were $98.2 \%$ and $52.3 \%$, respectively. After applying the HCF system, the water cut in the central wells dropped to $81.3 \%$, and oil production increased from 3.3 to 79.0 ton/day (see Fig. 5). The enhanced oil recovery was $8.5 \%$. The final oil recovery reached $63.6 \%$ OOIP.

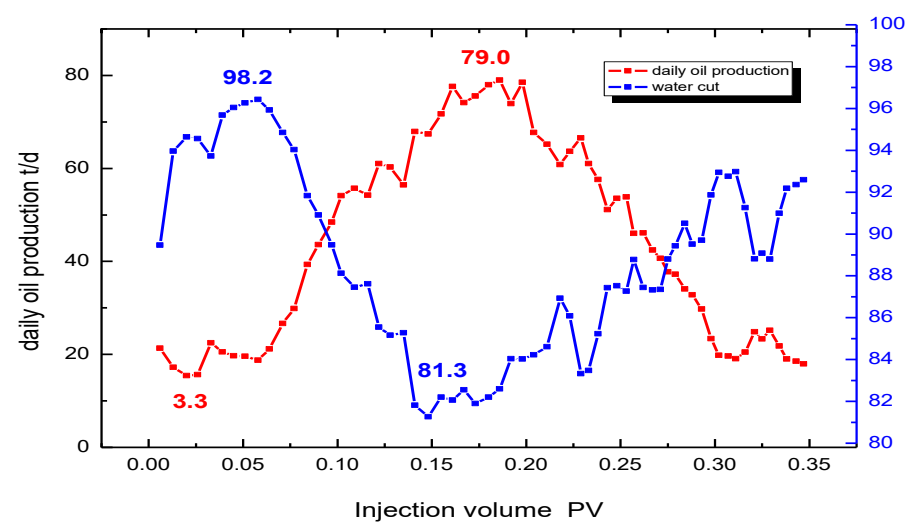

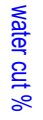

Fig. 5 Production curve of HCF pilot at Gudao's ZYQ Ng3 


\section{Summary}

In reservoirs in which oil recovery is difficult, such as those with high temperature and high salinity, class III, IV and V reservoirs, and reservoirs after polymer flooding, it is recommended to integrate chemical flooding material development based on theoretical and experimental research. Polymer flooding and SP flooding have achieved great success but require further improvements in order to be more applicable under severe reservoir conditions. HCF flooding has potential as new enhanced oil recovery opportunities for high-temperature, high-salinity and heterogeneous reservoir applications.

\section{Acknowledgements}

This work was financially supported by the National Science and Technology Major Project (2016ZX05011-003).

\section{References}

[1] F.Q.Yuan, H.C. Li, and Z.Q. Zhang: Oil \& gas Recovery Technology, Vol. 2(2000), p. 12.

[2] H.Q. Sun, Z.Q. Li, and X.L. Cao: SP technology (China Science and Technology Press, Beijing 2007).

[3] Z.Q. Li: Petroleum Exploration and Development, Vol. 31(2004), p. 119.

[4] Y. Li, and X.L. Cao: SPE 68697 (2000).

[5] H.Q. Sun: Petroleum Exploration and Development, Vol. 33(2006), p. 262.

[6] C.L. Wang, and X.L. Cao: SPE 38321(1997). 